\title{
The impact of achieving a sustained virological response with direct-acting antivirals on serum autotaxin levels in chronic hepatitis $C$ patients
}

\author{
Shereen Abou Bakr Saleh(1), Khaled Mohamed Abdelwahab, Asmaa Mady Mady and \\ Ghada Abdelrahman Mohamed*i(D)
}

\begin{abstract}
Background: Autotaxin (ATX) is an emerging biomarker for liver fibrosis. Achievement of sustained virological response (SVR) by direct-acting antivirals (DAAs) results in hepatic fibrosis regression in chronic hepatitis C (CHC) patients. In this context, the clinical implications of ATX have not yet been well-defined. In this study, we aimed to assess the impact of achieving SVR with DAA therapy on serum ATX levels and whether these levels can reflect the regression of hepatic fibrosis in CHC patients. We evaluated serum ATX levels at baseline and 12 weeks post-DAA therapy in $48 \mathrm{CHC}$ patients. We compared ATX with FIB4 score and AST-to-Platelet Ratio Index (APRI) as regards the detection of grade F3-4 fibrosis.

Results: Serum ATX levels were significantly declined in 47 patients after the achievement of SVR12 $(p<0.001)$. The diagnostic ability of ATX for the detection of grade F3-4 fibrosis was inferior to FIB4 and APRI scores at baseline and SVR12.

Conclusion: Achievement of SVR with DAA therapy causes a significant decline in serum autotaxin concentrations, suggesting early regression of hepatic fibrosis in CHC patients. However, its diagnostic capability for routine patient monitoring and follow-up is still under debate.
\end{abstract}

Keywords: Hepatitis C, Liver stiffness, Transient elastography, Direct-acting antivirals, Sustained virological response

\section{Background}

Hepatitis $\mathrm{C}$ virus (HCV) infection causes chronic hepatitis and ultimately progresses to cirrhosis and hepatocellular carcinoma (HCC) [1]. Persistent chronic hepatitis $\mathrm{C}(\mathrm{CHC})$ causes the transition of hepatic stellate cells to myofibroblasts, which results in excessive extracellular matrix synthesis [2].

The disease progression into cirrhosis, hepatic cell failure, and HCC was positively correlated with the hepatic histological features [3]. Hence, the estimation of hepatic fibrosis stage in $\mathrm{CHC}$ patients is essential for the

* Correspondence: ghadaabdelrahman@med.asu.edu.eg Gastroenterology and Hepatology Unit, Department of Internal Medicine, Faculty of Medicine, Ain Shams University, Cairo 11591, Egypt determination of therapeutic modalities and surveillance interval [4].

Liver biopsy is recommended as the golden method for the diagnosis of liver fibrosis [5]. However, it is an invasive procedure [6]; besides, it is not an optimal method for the detection of hepatic fibrosis due to the sampling errors, inter- and intra-observer variability, the risk of complications, and its cost [7]. These limitations have motivated the evolution of serum markers for the non-invasive evaluation of hepatic fibrosis. Serum markers are classified into direct and indirect markers whether they reflect the turnover of extracellular matrix [8].

Autotaxin (ATX) has been identified as a direct marker for hepatic fibrosis. It is also known as ectonucleotide pyrophosphatase/phosphodiesterase 2 (ENPP2), 
Table 1 Patients' characteristics at baseline and SVR12

\begin{tabular}{llll}
\hline & Baseline $(\boldsymbol{n}=\mathbf{4 8})$ & SVR12 $(\boldsymbol{n}=\mathbf{4 7})$ & $\boldsymbol{p}$ value \\
\hline ATX $(\mathrm{pg} / \mathrm{mL})$ & $500.5(399.5-667.5)$ & $404(331-518)$ & $<0.001$ \\
ALT $(\mathrm{IU} / \mathrm{L})$ & $42(28-54)$ & $21(17-25)$ & $<0.001$ \\
AST $(\mathrm{IU} / \mathrm{L})$ & $36.50(29-49)$ & $21(19-25)$ & $<0.001$ \\
Albumin $(\mathrm{mg} / \mathrm{dL})$ & $4.31 \pm 0.60$ & $4.47 \pm 0.48$ & 0.005 \\
Creatinine $(\mathrm{mg} / \mathrm{dL})$ & $0.86 \pm 0.21$ & $0.94 \pm 0.14$ & $<0.001$ \\
Total bilirubin $(\mathrm{mg} / \mathrm{dL})$ & $0.80(0.6-1)$ & $0.85(0.7-1)$ & 0.088 \\
WBC $\left(\times 10^{3} / \mu \mathrm{L}\right)$ & $6.48(5.4-8)$ & $5.60(4.68-6.50)$ & 0.007 \\
Platelets $(\mathrm{g} / \mathrm{dL})$ & $203.7 \pm 82.83$ & $204.9 \pm 53.67$ & 0.860 \\
Hemoglobin $(\mathrm{g} / \mathrm{dL})$ & $13.37 \pm 1.63$ & $13.15 \pm 1.55$ & 0.331 \\
INR & $1.07 \pm 0.14$ & $1.05 \pm 0.11$ & 0.009 \\
AFP (ng/mL) & $5.20 \pm 1.0$ & $4.52 \pm 0.71$ & $<0.001$ \\
MELD score & $7.45 \pm 1.76$ & $7.12 \pm 1.43$ & 0.045 \\
Child-Pugh score & $5.20 \pm 0.41$ & $5.10 \pm 0.31$ & 0.095 \\
APRI score & $0.46(0.28-0.92)$ & $0.25(0.21-0.34)$ & $<0.001$ \\
FIB4 score & $1.63(1.13-3.22)$ & $1.29(1.03-1.69)$ & $<0.001$ \\
LS (kPa) & $10.30(7.15-14.45)$ & $8.80(6.70-11.60)$ & $<0.001$ \\
\hline AFP apha-fetopoten & ALT &
\end{tabular}

AFP alpha-fetoprotein, ALT alanine aminotransferase, APRI AST-to-Platelet Ratio Index, AST aspartate aminotransferase, ATX autotaxin, INR international normalized ratio, $L S$ liver stiffness, MELD Model for End-Stage Liver Disease, WBC white blood cell count

a lysophospholipase D that hydrolyses lysophosphatidylcholine to lysophosphatidic acid (LPA) [9], a lipid mediator that stimulates $G$ protein-coupled receptors to elicit numerous cellular functions such as cell migration, angiogenesis, neurogenesis, platelet aggregation, smooth muscle contraction, and wound healing [10].

Physiologically, ATX circulates in the serum and is metabolized by hepatic sinusoidal endothelial cells [11]. Moreover, chronic hepatitis has been reported to induce ATX secretion from hepatocytes, and LPA has been shown to trigger hepatic stellate cells, promote their contraction, and inhibit their apoptosis [12]. Therefore, ATX metabolism is thought to be compromised in patients with hepatic fibrosis leading to higher serum ATX levels [11, 13].

It has been reported that ATX disrupts lipid homeostasis and contributes to the progress of both fibrosis and cancer [14]. Subsequently, raised serum ATX concentrations were identified in patients with $\mathrm{CHC}[15$, 16], hepatitis B virus [17], non-alcoholic fatty liver disease [18], and primary biliary cholangitis [19], suggesting
ATX as a biomarker for chronic liver diseases regardless of the initiating insult. Moreover, ATX expression was increased in HCC [12], and it was associated with an increased cellular invasion [20] and poor prognosis [21].

Additionally, increased serum ATX concentrations were correlated with the histological grade of hepatic fibrosis [15] and the Child-Pugh score, demonstrating the linkage of ATX and disease severity in cirrhotic patients [13]. Furthermore, low serum ATX concentrations were significantly correlated with longer survival time, further proposing ATX as a prognostic marker of the severity of hepatic disease [13].

Therefore, ATX is a new participant in the pathological process of hepatic fibrosis and HCC and a possible novel target for therapy. Hence, a substantial effort has been dedicated to creating synthetic ATX inhibitors as adjuvant therapy in hepatic fibrosis and HCC [22].

For HCV eradication, direct-acting antivirals (DAAs) achieved sustained virological response (SVR) in over $90 \%$ of treated patients [23]. However, in spite of viral eradication, the risk of the progression of hepatic fibrosis to cirrhosis and HCC remains [24]. Hence, hepatic fibrosis should be monitored after DAA therapy.

Several reports suggested that the achievement of SVR with DAA therapy improves hepatic fibrosis in $\mathrm{CHC}$ patients [23, 25]; however, the changes of serum ATX levels have been investigated in scarce studies in this context [16, 26-28] and its ability to reflect the regression of hepatic fibrosis remains uncertain. Therefore, we aimed to investigate the impact of achieving SVR with DAA therapy on serum ATX levels and whether these levels can reflect the regression of hepatic fibrosis in $\mathrm{CHC}$ patients.

\section{Methods}

This prospective study included $48 \mathrm{CHC}$ patients, all of whom were eligible for DAA therapy. For 12 weeks, 35 patients were treated with sofosbuvir/daclatasvir, and 13 patients were treated with sofosbuvir/daclatasvir and a weight-based dose of ribavirin, between September 2018 and Mars 2019, at Damanhour Medical National Institute, Beheira, Egypt.

Inclusion criteria were treatment-naïve $\mathrm{CHC}$ patients who were older than 18 years. The diagnosis of $\mathrm{CHC}$ was based on the existence of serum HCV antibodies and detectable HCV RNA. Exclusion criteria were

Table 2 Serum ATX levels at baseline and SVR12 according to gender

\begin{tabular}{lllll}
\hline & & Males $(\boldsymbol{n}=\mathbf{2 3})$ & \multicolumn{1}{c}{ Females $(\boldsymbol{n}=\mathbf{2 4})$} & $\boldsymbol{p}$ value \\
\hline Serum ATX level $(\mathrm{pg} / \mathrm{mL})$, median $(\mathrm{IQR})$ & Baseline & $500(419.50-691)$ & $501.50(390-637.5)$ & 0.798 \\
& SVR12 & $393(343-588)$ & $406(329-510.75)$ \\
$p$ value & & $<0.001$ & $<0.001$ \\
\hline
\end{tabular}

ATX autotaxin, $I Q R$ interquartile range 


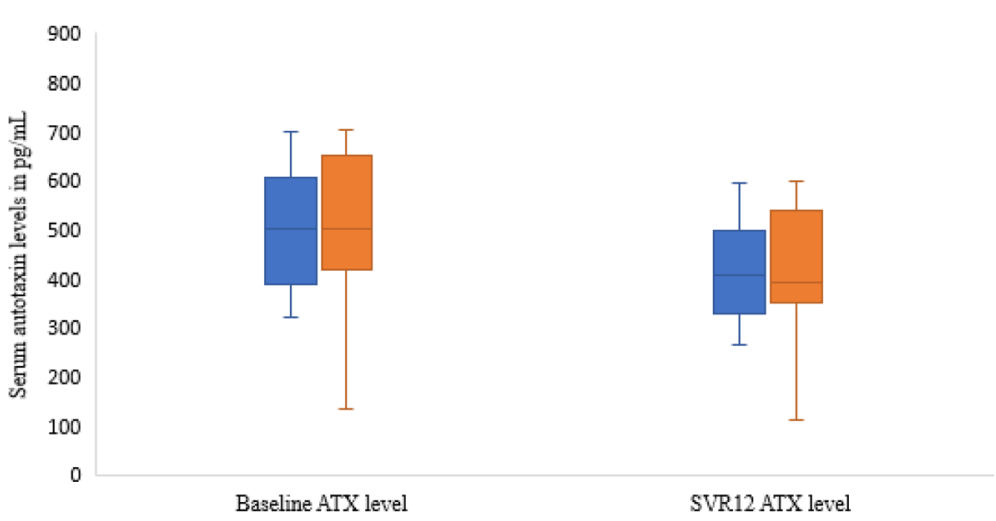

Fig. 1 Serum autotaxin levels in male and female patients at baseline and SVR12

patients who had another etiology of hepatic disease (autoimmune hepatitis, primary biliary cirrhosis, alcoholic liver disease, or non-alcoholic fatty liver disease), decompensated hepatic disease (bilirubin $>3 \mathrm{mg} / \mathrm{dL}$, serum albumin $<2.8 \mathrm{mg} / \mathrm{dL}$, INR $>1.8$, platelets $<50 \times$ $10^{3}$ ), HCC, renal impairment, previous anti-HCV-viral therapy, liver transplantation, and HBsAg or HIVpositive patients.

For all patients, we evaluated serum samples and non-invasive methods for liver fibrosis assessment at baseline and 12 weeks post-treatment. SVR12 was defined as undetectable serum HCV RNA at 12 weeks post-treatment.

The study protocol conformed to the ethical guidelines of the 1975 Declaration of Helsinki and its appendices and was approved by the Ethics Committee of the Faculty of Medicine, Ain Shams University (FWA
000017585). Written informed consent was obtained from each patient included in the study.

\section{Detection of ATX}

We estimated serum ATX concentrations by a sandwich ELISA detection method (Cat No. SG-10887, SinoGeneClon Biotech Co., Ltd., China), with a detection range of 60-2200 $\mathrm{pg} / \mathrm{mL}$ and sensitivity of $5 \mathrm{pg} / \mathrm{mL}$, and intra- and inter-assay coefficients of variation were $<8 \%$ and $<10 \%$, respectively.

\section{Liver stiffness evaluation}

The liver stiffness (LS) was estimated using Fibroscan ${ }^{\circ}$ (Echosens, 502 Touch, Paris, France). The median LSM in kilopascals $(\mathrm{kPa})$ was reported. According to Tsochatzis et al. [29], the following fibrosis staging cutoff values were used: F0-F1 $<7 \mathrm{kPa}, \mathrm{F} 2=7-9.4 \mathrm{kPa}, \mathrm{F} 3=9.5-$ $11.9 \mathrm{kPa}$, and F4 > $12 \mathrm{kPa}$.

$\square$ Baseline $\square$ SVR12

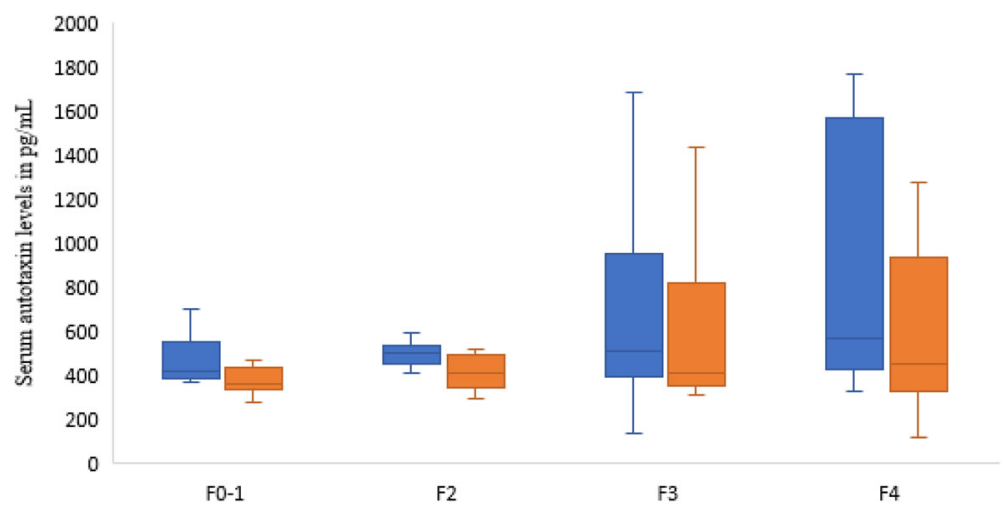

Fig. 2 The sequential changes in serum autotaxin levels according to the grade of fibrosis after achieving SVR12. SVR, sustained virological response 
Table 3 Serum ATX levels according to the fibrosis grade at baseline and SVR12

\begin{tabular}{|c|c|c|c|c|c|c|}
\hline & & F0-1 & F2 & F3 & F4 & $p$ value \\
\hline \multirow[t]{2}{*}{$\begin{array}{l}\text { Serum ATX level }(\mathrm{pg} / \mathrm{mL}) \text {, median } \\
\text { (IQR) }\end{array}$} & Baseline & $420(371.25-595)$ & 501 (444-547) & $512(390-1443)$ & $\begin{array}{l}549(393.75- \\
1552.25)\end{array}$ & $\begin{array}{l}0.389^{\mathrm{a}} \\
0.043^{b^{\prime}}\end{array}$ \\
\hline & SVR12 & $\begin{array}{l}361.50(334- \\
445.75)\end{array}$ & $\begin{array}{l}404.50(322- \\
489)\end{array}$ & $\begin{array}{l}417.50(371.50- \\
1260.25)\end{array}$ & $451(320-1275)$ & $\begin{array}{l}0.569^{a} \\
0.083^{b^{\prime}}\end{array}$ \\
\hline$p$ value & & 0.003 & $<0.001$ & 0.031 & $<0.001$ & \\
\hline
\end{tabular}

$A T X$ autotaxin, IQR interquartile range

${ }^{a}$ Kruskal-Wallis test

bJonckheere-Terpstra test

\section{Liver fibrosis scores}

The Aspartate-to-Platelet Ratio Index (APRI) and Fibrosis 4 (FIB4) scores were evaluated using the following formulas:

APRI score $=($ AST/upper limit of normal AST $[\mathrm{IU} / \mathrm{L}])$ $\times\left(100 /\right.$ platelet count $\left.\left[10^{9} / \mathrm{L}\right]\right)[30]$.

FIB4 score $=[$ Age $($ years $) \times$ AST $($ IU $/ L)] /[$ platelet count $\left.\left(10^{9} / \mathrm{L}\right) \times \sqrt{\operatorname{ALT}(\mathrm{IU} / \mathrm{L})}\right][31]$.

\section{Statistical analysis}

Data were analyzed using IBM SPSS Statistics for Windows, version 20 (IBM Corp., Armonk, NY, USA). Qualitative data were described using numbers and percentages. Quantitative data were described using the mean \pm standard deviation (SD) or median and interquartile range (IQR). The McNemar test was used to analyze paired nominal variables. A paired $t$ test was used for normally distributed quantitative variables. The MannWhitney test, Wilcoxon signed-rank test, or KruskalWallis test with post hoc Dunn's test was used for abnormally distributed quantitative variables, as appropriate. The trends in the serum ATX concentrations in accordance with the fibrosis stage were assessed using the Jonckheere-Terpstra test. Spearman's rank correlation coefficient was used for the correlation between two abnormally distributed quantitative variables. The sensitivities and specificities of ATX and the fibrosis scores were estimated using receiver operating characteristic curve (ROC) analysis. A value of $p<0.05$ was considered significant.

\section{Results}

We enrolled $48 \mathrm{CHC}$ patients, 23 (47.9\%) males and 25 $(52.1 \%)$ females, with a mean age of $54.92 \pm 10.72$ years.
All the patients completed the treatment regimen and follow-up. Forty-seven (97.7\%) patients achieved SVR12. Thirty-eight (79.2\%) and 10 (20.8\%) patients had ChildPugh score A5 and A6 at baseline, while 42 (87.5\%) and 6 (12.5\%) patients had Child-Pugh score A5 and A6 at 12 weeks post-treatment.

Serum ATX concentrations were significantly decreased in the 47 patients who achieved SVR12 [404 (331-518) vs. 500.5 (399.5-667.5) pg/mL; $p<0.001$ ] (Table 1). The same significant decrease in serum ATX levels after treatment was also reproduced by patient stratification according to gender $(p<0.001)$ (Table 2 and Fig. 1). Female patients had higher, but not significantly, serum ATX levels compared to male patients at baseline and SVR12 (Table 2 and Fig. 1). The non-SVR patient had the highest ATX value at baseline and 12 weeks post-treatment $(6028$ and $5128 \mathrm{pg} / \mathrm{mL}$, respectively).

We observed that serum ATX levels increased concomitantly with the grade of liver fibrosis (Fig. 2). In addition, those levels were significantly decreased in each fibrosis grade at SVR12 (Table 3).

LS, FIB4, and APRI scores were also significantly decreased at SVR12 (Table 1 and Table S1). Additionally, there were statistically significant differences in ALT, AST, albumin, creatinine, white blood cell count, international normalized ratio, alphafetoprotein (AFP), and MELD score at SVR12 compared with baseline (Table 1).

No significant correlations were detected between serum ATX levels and patients' characteristics (Table S2).

The diagnostic performance of ATX for the differentiation of grade F3-4 hepatic fibrosis was inferior to FIB4 and APRI scores at baseline and SVR12 (Tables 4 and 5 and Figures S1\&S2).

Table 4 The diagnostic performance for the detection of grade F3-4 fibrosis at baseline

\begin{tabular}{|c|c|c|c|c|c|c|c|c|c|}
\hline \multirow[t]{2}{*}{ Criterion } & \multirow{2}{*}{$\begin{array}{l}\text { Cutoff } \\
\text { value }\end{array}$} & \multirow[t]{2}{*}{ AUC } & \multirow{2}{*}{$\begin{array}{l}\mathrm{Se} \\
(\%)\end{array}$} & \multirow{2}{*}{$\begin{array}{l}\text { Sp } \\
(\%)\end{array}$} & \multirow[t]{2}{*}{ PPV } & \multirow[t]{2}{*}{ NPV } & \multicolumn{2}{|c|}{ 95\% confidence limits } & \multirow{2}{*}{$\begin{array}{l}p \\
\text { value }\end{array}$} \\
\hline & & & & & & & Upper & Lower & \\
\hline$\overline{\text { ATX }}$ & $\geq 448 \mathrm{pg} / \mathrm{mL}$ & 0.520 & 65.3 & 42.8 & 0.586 & 0.500 & 0.331 & 0.668 & 0.407 \\
\hline FIB4 & $\geq 1.26$ & 0.895 & 96.1 & 61.9 & 0.757 & 0.928 & 0.766 & 0.955 & $<0.001$ \\
\hline APRI & $\geq 0.32$ & 0.858 & 96.1 & 61.9 & 0.757 & 0.928 & 0.705 & 0.934 & $<0.001$ \\
\hline
\end{tabular}


Table 5 The diagnostic performance for the detection of grade F3-4 fibrosis at SVR12

\begin{tabular}{|c|c|c|c|c|c|c|c|c|c|}
\hline \multirow[t]{2}{*}{ Criterion } & \multirow{2}{*}{$\begin{array}{l}\text { Cutoff } \\
\text { value }\end{array}$} & \multirow[t]{2}{*}{ AUC } & \multirow{2}{*}{$\begin{array}{l}\mathrm{Se} \\
\text { (\%) }\end{array}$} & \multirow{2}{*}{$\begin{array}{l}\text { Sp } \\
(\%)\end{array}$} & \multirow[t]{2}{*}{ PPV } & \multirow[t]{2}{*}{ NPV } & \multicolumn{2}{|c|}{ 95\% confidence intervals } & \multirow{2}{*}{$\begin{array}{l}p \\
\text { value }\end{array}$} \\
\hline & & & & & & & Upper & Lower & \\
\hline ATX & $\geq 381 \mathrm{pg} / \mathrm{mL}$ & 0.579 & 52.9 & 36.6 & 0.344 & 0.578 & 0.378 & 0.728 & 0.186 \\
\hline FIB4 & $\geq 1.11$ & 0.715 & 70.5 & 36.6 & 0.406 & 0.687 & 0.517 & 0.840 & 0.003 \\
\hline APRI score & $\geq 0.24$ & 0.645 & 76.4 & 50 & 0.464 & 0.789 & 0.458 & 0.778 & 0.035 \\
\hline
\end{tabular}

ATX autotaxin, APRI AST-to-Platelet Ratio Index, AUC area under the curve, NPV negative predictive value, PPV positive predictive value, Se sensitivity, Sp specificity

\section{Discussion}

$\mathrm{CHC}$ patients manifest persistent inflammatory changes and fibrogenesis throughout the clinical course of the disease even after the progression to cirrhosis [32]. DAA therapy achieved extremely high SVR rates, consequently suppressing the hepatic inflammation and hindering the progress of fibrosis. However, the extent of hepatic fibrosis regression should be assessed to decide which individuals remain at a high risk of HCC. Therefore, simple and reliable non-invasive methods are required to achieve this goal [16]; however, the value of serum biomarkers for the evaluation of liver fibrosis following DAA therapy has not been well evaluated [27].

We detected that serum ATX concentrations were significantly decreased in $\mathrm{CHC}$ patients after achieving SVR12. This is supported by the findings of other studies [16, 26-28]. This significant difference was reproduced when classifying the patients according to gender, as previously proposed [16, 17, 27, 33].

ATX levels were higher in females than in males at baseline and SVR12; however, the exact rationale for this difference remains under debate. Ferry et al. [34] concluded that there is excess ATX expression in, and release from, adipocytes, which occupy a more significant volume in adipose tissues in females than in males [35], suggesting that as the reason for gender difference. However, this hypothesis should be investigated in further studies.

It was reported that serum ATX concentrations correlate with the hepatic fibrosis grade [15], that is, the progression of fibrosis leads to impaired ATX clearance through the dysfunction of endothelial cells [13]. Consistent with this hypothesis, we observed an increasing trend of serum ATX with the progression of hepatic fibrosis grade.

Our results partially agree with Ando et al. who concluded that serum ATX levels significantly declined from baseline to SVR12 in patients with F4 fibrosis grade, while no changes were detected in patients with F2 and F3 fibrosis grades [27].

In accordance with previous reports [16, 28], serum ALT and AFP levels were also significantly decreased at SVR12. Based on the fact that elevated ALT and AFP levels reflect hepatic inflammatory changes and regeneration, and ATX is linked to the promotion of hepatic fibrosis [12, 15], these findings may indicate an improvement of necroinflammatory changes and possibly early regression of hepatic fibrosis that occurred after DAA therapy.

Contrary to previous studies $[13,26-28,33]$, no correlations were detected between serum ATX concentrations and LS, fibrosis indices, or laboratory investigations in our study cohort. This discrepancy could be attributed to the fact that all our patients are Child-Pugh class A and unequal sample size.

We detected that the diagnostic performance of ATX in predicting grade F3-4 hepatic fibrosis was inferior to FIB4 and APRI scores at baseline and SVR12. In contrast, in Yamazaki et al.'s study [15], the AUC of ATX (0.788) was comparable to those of FIB4 score (0.814) and APRI (0.780).

The limitations of the current study are the lack of a paired histological evaluation due to the invasiveness of hepatic biopsy and the small number of patients who failed to achieve SVR12. Further large-scale studies with a long-term followup should be performed to determine whether the changes in serum ATX concentrations can reflect the regression of liver fibrosis and the incidence rates of $\mathrm{HCC}$ in $\mathrm{CHC}$ patients after achieving SVR with DAA therapy.

\section{Conclusion}

Achievement of SVR with DAA therapy causes a significant decline in serum autotaxin concentrations, suggesting early regression of hepatic fibrosis in $\mathrm{CHC}$ patients. However, its diagnostic capability for routine patient monitoring and follow-up is still under debate.

\section{Supplementary Information}

The online version contains supplementary material available at https://doi. org/10.1186/s43066-020-00060-w.

Additional file 1: Figure S1. ROC curve for the detection of grade F3-4 fibrosis at baseline. Figure S2. ROC curve for the detection of grade F3-4 fibrosis at SVR12. Table S1. Patients' liver stiffness at baseline and SVR12. Table S2. Correlation between ATX and patients' characteristics at baseline and SVR12.

\section{Abbreviations}

AFP: Alpha-fetoprotein; APRI: Aspartate-to-Platelet Ratio Index; ATX: Autotaxin; CHC: Chronic hepatitis C; DAAs: Direct-acting antivirals; ENPP2: Ectonucleotide pyrophosphatase/phosphodiesterase 2; FIB4: Fibrosis 4 score; HBsAg: Hepatitis B surface antigen; HCC: Hepatocellular carcinoma; HCV: Hepatitis C virus; HIV: Human immunodeficiency virus;

LPA: Lysophosphatidic acid; SVR: Sustained virological response 


\section{Acknowledgements}

Not applicable

\section{Authors' contributions}

SS, KA, and GM contributed to the design of the study; AM contributed to the acquisition of data; SS, KA, AM, and GM participated in the analysis and interpretation of the data, and revised the article critically for relevant intellectual content; GM participated in the statistical evaluations and wrote the manuscript. All authors have read and approved the manuscript.

\section{Funding}

This research did not receive any specific grant from funding agencies in the public, commercial, or not-for-profit sectors.

\section{Availability of data and materials}

The datasets used and analyzed during the current study are available from the corresponding author on reasonable request.

\section{Ethics approval and consent to participate}

Approval was obtained from the Ethics Committee of the Faculty of Medicine, Ain Shams University (FWA 000017585). Informed written consent was obtained from each participant before enrollment in the study. This study was performed in accordance with the 1975 principles of the Declaration of Helsinki and its appendices.

\section{Consent for publication}

Not applicable

\section{Competing interests}

The authors declare that they have no competing interests.

Received: 10 June 2020 Accepted: 26 October 2020

Published online: 09 November 2020

\section{References}

1. Ansaldi F, Orsi A, Sticchi L, Bruzzone B, Icardi G (2014) Hepatitis C virus in the new era: perspectives in epidemiology, prevention, diagnostics and predictors of response to therapy. World J Gastroenterol 20:9633-9652

2. Yamaoka K, Nouchi T, Marumo F, Sato C (1993) Alpha-smooth-muscle actin expression in normal and fibrotic human livers. Dig Dis Sci 38:1473-1479

3. Ge PS, Runyon BA (2016) Treatment of patients with cirrhosis. N Engl J Med 375:767-777

4. Yano M, Kumada H, Kage M, Ikeda K, Shimamatsu K, Inoue O, Hashimoto E, Lefkowitch JH et al (1996) The long-term pathological evolution of chronic hepatitis C. Hepatology 23:1334-1340

5. Angulo P (2002) Nonalcoholic fatty liver disease. N Engl J Med 346:12211231

6. Neuman MG, Cohen LB, Nanau RM (2016) Hyaluronic acid as a non-invasive biomarker of liver fibrosis. Clin Biochem 49:302-315

7. Bedossa P, Carrat F (2009) Liver biopsy: the best, not the gold standard. J Hepatol 50:1-3

8. Papastergiou V, Tsochatzis E, Burroughs AK (2012) Non-invasive assessment of liver fibrosis. Ann Gastroenterol 25:218-231

9. Aikawa S, Hashimoto T, Kano K, Aoki J (2015) Lysophosphatidic acid as a lipid mediator with multiple biological actions. J Biochem 157:81-89

10. Moolenaar WH, van Meeteren LA, Giepmans BN (2004) The ins and outs of lysophosphatidic acid signaling. Bioessays 26:870-881

11. Jansen $S$, Andries M, Vekemans K, Vanbilloen $H$, Verbruggen A, Bollen M (2009) Rapid clearance of the circulating metastatic factor autotaxin by the scavenger receptors of liver sinusoidal endothelial cells. Cancer Lett 284: 216-221

12. Kaffe E, Katsifa A, Xylourgidis N, Ninou I, Zannikou M, Harokopos V, Foka P, Dimitriadis A et al (2017) Hepatocyte autotaxin expression promotes liver fibrosis and cancer. Hepatology 65:1369-1383

13. Pleli T, Martin D, Kronenberger B, Brunner F, Köberle V, Grammatikos G, Farnik H, Martinez $Y$ et al (2014) Serum autotaxin is a parameter for the severity of liver cirrhosis and overall survival in patients with liver cirrhosis--a prospective cohort study. PLoS One 9:e103532

14. Nakamura K, Ohkawa R, Okubo S, Tozuka M, Okada M, Aoki S, Aoki J, Arai H et al (2007) Measurement of lysophospholipase D/autotaxin activity in human serum samples. Clin Biochem 40:274-277
15. Yamazaki T, Joshita S, Umemura T, Usami Y, Sugiura A, Fujimori N, Shibata S, chikawa Y et al (2017) Association of serum autotaxin levels with liver fibrosis in patients with chronic hepatitis C. Sci Rep 7:46705

16. Yamazaki T, Joshita $S$, Umemura $T$, Usami $Y$, Sugiura A, Fujimori N, Kimura T, Matsumoto A et al (2018) Changes in serum levels of autotaxin with directacting antiviral therapy in patients with chronic hepatitis C. PLoS One 13: e0195632

17. Joshita S, Ichikawa Y, Umemura T, Usami Y, Sugiura A, Shibata S, Yamazaki T, Fujimori $\mathrm{N}$ et al (2018) Serum autotaxin is a useful liver fibrosis marker in patients with chronic hepatitis B virus infection. Hepatol Res 48:275-285

18. Fujimori N, Umemura T, Kimura T, Tanaka N, Sugiura A, Yamazaki T, Joshita S, Komatsu M et al (2018) Serum autotaxin levels are correlated with hepatic fibrosis and ballooning in patients with non-alcoholic fatty liver disease. World J Gastroenterol 24:1239-1249

19. Joshita S, Umemura T, Usami Y, Yamashita Y, Norman GL, Sugiura A Yamazaki T, Fujimori $\mathrm{N}$ et al (2018) Serum autotaxin is a useful disease progression marker in patients with primary biliary cholangitis. Sci Rep 8 : 8159

20. Wu JM, Xu Y, Skill NJ, Sheng H, Zhao Z, Yu M, Saxena R, Maluccio MA (2010) Autotaxin expression and its connection with the TNF-alpha-NF-kappaB axis in human hepatocellular carcinoma. Mol Cancer 9:71

21. Enooku K, Uranbileg B, Ikeda H, Kurano M, Sato M, Kudo H, Maki H, Koike K et al (2016) Higher LPA2 and LPA6 mRNA levels in hepatocellular carcinoma are associated with poorer differentiation, microvascular invasion and earlier recurrence with higher serum autotaxin levels. PLoS One 11:e0161825

22. Baader M, Bretschneider T, Broermann A, Rippmann JF, Stierstorfer B, Kuttruff CA, Mark M (2018) Characterization of the properties of a selective, orally bioavailable autotaxin inhibitor in preclinical models of advanced stages of liver fibrosis. Br J Pharmacol 175:693-707

23. Saleh S, Salama M, Alhusseini M, Mohamed G (2020) M2BPGi for assessing liver fibrosis in patients with hepatitis $C$ treated with direct-acting antivirals. World J Gastroenterol 26:2864-2876

24. Nagaoki Y, Imamura M, Aikata H, Daijo K, Teraoka Y, Honda F, Nakamura Y, Hatooka M et al (2017) The risks of hepatocellular carcinoma development after HCV eradication are similar between patients treated with peginterferon plus ribavirin and direct-acting antiviral therapy. PLoS One 12 e0182710

25. Bachofner JA, Valli PV, Kröger A, Bergamin I, Künzler P, Baserga A, Braun D, Seifert B et al (2017) Direct antiviral agent treatment of chronic hepatitis C results in rapid regression of transient elastography and fibrosis markers fibrosis-4 score and aspartate aminotransferase-platelet ratio index. Liver Int 37:369-376

26. Kostadinova L, Shive $\mathrm{CL}$, Judge C, Zebrowski E, Compan A, Rife K, Hirsch A, Falck-Ytter $Y$ et al (2016) During hepatitis C virus (HCV) infection and HCVHIV coinfection, an elevated plasma level of autotaxin is associated with lysophosphatidic acid and markers of immune activation that normalize during interferon-free HCV therapy. J Infect Dis 214:1438-1448

27. Ando W, Yokomori H, Kaneko F, Kaneko M, Igarashi K, Suzuki H (2018) Serum autotaxin concentrations reflect changes in liver stiffness and fibrosis after antiviral therapy in patients with chronic hepatitis C. Hepatol Commun 2:1111-1122

28. Kostadinova L, Shive CL, Zebrowski E, Fuller B, Rife K, Hirsch A, Compan A, Moreland $A$ et al (2018) Soluble markers of immune activation differentially normalize and selectively associate with improvement in AST, ALT, albumin, and transient elastography during IFN-free HCV therapy. Pathog Immun 3:149-163

29. Tsochatzis EA, Gurusamy KS, Ntaoula S, Cholongitas E, Davidson BR, Burroughs AK (2011) Elastography for the diagnosis of severity of fibrosis in chronic liver disease: a meta-analysis of diagnostic accuracy. J Hepatol 54: 650-659

30. Wai CT, Greenson JK, Fontana RJ, Kalbfleisch JD, Marrero JA, Conjeevaram HS, Lok AS (2003) A simple noninvasive index can predict both significant fibrosis and cirrhosis in patients with chronic hepatitis C. Hepatology 38 518-526

31. Sterling RK, Lissen E, Clumeck N, Sola R, Correa MC, Montaner J, S Sulkowsk M, Torriani FJ et al (2006) Development of a simple noninvasive index to predict significant fibrosis in patients with HIV/HCV coinfection. Hepatology 43:1317-1325

32. van Meeteren LA, Ruurs $P$, Stortelers $C$, Bouwman $P$, van Rooijen MA, Pradère JP, Pettit TR, Wakelam MJ et al (2006) Autotaxin, a secreted lysophospholipase D, is essential for blood vessel formation during development. Mol Cell Biol 26:5015-5022 
33. Shao X, Uojima H, Setsu T, Okubo T, Atsukawa M, Furuichi Y, Arase Y, Hidaka $\mathrm{H}$ et al (2020) Usefulness of autotaxin for the complications of liver cirrhosis. World J Gastroenterol 26:97-108

34. Ferry G, Tellier E, Try A, Grés S, Naime I, Simon MF, Rodriguez M, Boucher J et al (2003) Autotaxin is released from adipocytes, catalyzes lysophosphatidic acid synthesis, and activates preadipocyte proliferation. Up-regulated expression with adipocyte differentiation and obesity. J Biol Chem 278:18162-18169

35. Benesch MG, Ko YM, McMullen TP, Brindley DN (2014) Autotaxin in the crosshairs: taking aim at cancer and other inflammatory conditions. FEBS Lett 588:2712-2727

\section{Publisher's Note}

Springer Nature remains neutral with regard to jurisdictional claims in published maps and institutional affiliations.

\section{Submit your manuscript to a SpringerOpen ${ }^{\odot}$ journal and benefit from:}

- Convenient online submission

- Rigorous peer review

- Open access: articles freely available online

- High visibility within the field

- Retaining the copyright to your article

Submit your next manuscript at $\boldsymbol{\nabla}$ springeropen.com 